\title{
LA PRESENCIA DE LAS IDEAS POLÍTICAS DE SAMUEL PUFENDORF DURANTE LA INDEPENDENCIA DE CHILE
}

\author{
Fernando Pérez Godoy* \\ Universidad de Mainz, Alemania \\ fernandoperezgodoy@gmail.com
}

in Erinnerung an Claudia

\begin{abstract}
RESUMEN: Este artículo tiene como finalidad explicar la difusión y proliferación de las obras políticas del jurista luterano Samuel Pufendorf en el período de Revoluciones Modernas del siglo XVIII y XIX. Tales obras habrían sido parte del cuerpo de obras clásicas ilustradas citadas como imprescindibles en el restringido ámbito de las ideas políticas modernas del debate publicista de la naciente República chilena.
\end{abstract}

Palabras clave: Derecho Natural Moderno, Pufendorf, ilustración, independencia.

\begin{abstract}
The aim of this article is to explain the diffusion and propagation of jurist lutheran Samuel Pufendorf's politics works in the modern revolution period of the eighteenth and nineteenth centuries. His works have been part of the body of classic and illustrates work which were cited as essential in the restricted scope of politic modern ideas during the publicist debate in the birth of the chilean republic.
\end{abstract}

Keywords: Modern Natural Law, Pufendorf, enlightenment, independence.

Se sabe que los hombres de letras en Chile, a pesar de la censura del Estado borbónico y del control sobre el ámbito cultural de la Iglesia Católica, poseían algunas de las obras ilustradas y difundieron sus ideas entre los círculos aristocráticos, dejando de lado la consternación provocada por la Revolución Francesa en el país y reinterpretando ideas políticas acerca de cómo organizarse políticamente ante la acefalia monárquica de 1810. La presencia de estas obras no significa influencia ni menos causa de procesos políticos relativos a la Independencia, más bien, parece ser que ellas componen una pequeña isla que disfrutaron algunos cuantos letrados aficionados ${ }^{1}$.

Lo importante no fue si la aristocracia manejaba perfectamente estas ideas ilustradas modernas o las interpretó correctamente conforme a su autor. Lo fundamental, a la luz de los hechos, es saber si fueron referentes o incluso determinantes en la toma de decisiones en la

Universidad de Mainz, Alemania. Magíster en Historia Pontificia Universidad Católica de Valparaíso, estudiante primer semestre Doctorado en Historia Historisches Seminar, Neuere Geschichte, Johannes Gutenberg Universität Mainz.

1 Villalobos, Sergio. Tradición y Reforma en 1810. Santiago, Chile: Editorial Universitaria, Ediciones de la Universidad de Chile, 1961, p. 73. 
opinión pública de entonces ${ }^{2}$. El resultado institucional y conclusión en el ámbito de la teoría y pensamiento político a la que llegaron aquellos hombres de letras es claro y conocido: una forma de organización política moderna. Independiente de si era su intención o no, y teniendo en cuenta la complejidad de la coyuntura y de los procesos económicos y políticos que se venían gestando tanto en América como en Europa, Chile se convirtió en República. Es decir, la elección de un modelo republicano finalmente significó también la instauración irremediablemente, no muchas veces de forma consciente y proyectada, de una nueva visión de la legitimidad política y la naturaleza del poder ${ }^{3}$.

En este contexto netamente teórico-intelectual que habría sustentado el presunto proyecto político de la elite criolla luego de 1810 , no son pocas las citas de los historiadores nacionales a obras y autores europeos específicos que parecieron determinantes dentro del catálogo de libros disponibles para la reflexión política y social a fines del siglo XVIII y comienzos del $\mathrm{XIX}^{4}$. Entre ellos ocupan un lugar destacado, pero no muchas veces estudiado, los clásicos de la Ley Natural moderna. Es así como se cuentan someramente citados Iure belli ac pacis del jurista holandés Hugo Grocio (1589- 1645) y con mayor acento De iure naturae et Gentium y Officcio Hominis del profesor, historiador y jurista luterano Samuel Pufendorf (1632-1689) 5 . Muchos historiadores han hecho referencia a la existencia de las obras de Pufendorf como lo testimonia el Bosquejo Histórico de José Victorino Lastarria, el Discurso pronunciado con motivo de la inauguración del primer Congreso Nacional, de Juan Martínez de Rozas, y la obra Principio de Derecho Internacional de Andrés Bello, a lo que se suman las referencias ocasionales y pasajeras de historiadores como Mario Góngora, Jaime Eyzaguirre, Simón Collier, Alfredo Jocelyn-Holt, Marco Huesbe y Cristián Gazmuri ${ }^{6}$. La intención de este artículo es saber simplemente en qué sentido aparecen citados estos pensadores del Estado Moderno y qué habrían significado sus obras e ideas para aquellos hombres que debían afrontar el desafío institucional del autogobi-

2 Stuven, Ana María. La Seducción de un Orden Las Elites y la construcción de Chile en las polémicas culturales y políticas del siglo XIX. Santiago, Chile: Ediciones Universidad Católica de Chile, 2000, p. 66.

$3 \quad$ Ibid. p. 32 y ss.

4 En ese sentido, las obras de Robertson, W. Historia de América e Historia Filosófica y Raynal, G. Politica de los establecimientos europeos en las dos Indias parecen ser las más leídas e importantes. Villalobos, Sergio. op cit. (n.1), p. 126. Un estudio reciente para el caso de tratadistas franceses Vs. Castillo, Vasco. La Creación de la Republica La Filosofía Pública en Chile 1810-1830. Santiago, Chile: Editorial LOM, 2009, p. 21.

5 Para datos biográficos. Vs. Huesbe Llanos, Marco A. "La teoría política de Samuel Pufendorf a través de su comentario a la constitución del imperio romano-germánico (1667)”, en: Revista Estudios Históricos -Jurídicos. <en línea> 2009 , n.31 [citado el 13 de Enero de 2011], pp. 427-445. Disponible en la World Wide Web:<http://www.scielo.cl/scielo.php?script=sci_artte $\mathrm{xt} \&$ pid $=$ S071654552009000100016\&lng=es\&nrm=iso $>$.

6 Vs. Eyzaguirre, Jaime. Ideario y Ruta de la Emancipación chilena. -24a edición- Santiago, Chile: Editorial Universitaria, 1996, p. 73. Collier, Simon. Ideas and Politics of chilean Independence 1808-183. Cambridge, Inglaterra: Cambridge University Press, 1967, p. 169. Jocelyn-Holt, Alfredo. La Independencia de Chile Tradición, Modernización y Mito -2a. Edición- Santiago, Chile: Editorial Planeta/Ariel, 1999, p. 111. Góngora, Mario. Studies in the Colonial History of Spanish America. Cambridge, Inglaterra: Cambridge University Press, Tradución: Richard Southern, 1975, p. 16. GAZmuri, Cristián, Libros e ideas políticas ilustradas en la independencia de Chile. En: Loyola, Manuel y Grez, Sergio (comp.). Los proyectos Nacionales en el Pensamiento Politico y Social Chileno del Siglo XIX. Santiago, Chile: Ediciones UCSH, 2002, p. 13. Gazmuri, Cristian y Krebs, Ricardo (comp.). La Revolución Francesa y Chile. Santiago, Chile: Ediciones Universitarias, 1999, p. 21. 
erno y la formación de un orden político autónomo y nuevo. ¿Qué obras se conocían de Pufendorf en Chile y por qué habrían llegado a nuestro país dentro de aquella literatura censurada y subversiva que, como dice Gazmuri, por el mismo hecho encantaba a la elite intelectual.? Intentaré entonces responder por qué habría sido importante su presencia y, por sobre ello, desde una mirada histórica en este balance bicentenario, del porqué de la fama y divulgación de su obra en el debate intelectual durante la época de las Revoluciones Democráticas Modernas ${ }^{7}$. Su estudio, como el del resto de las obras que componen los llamados clásicos de la Ilustración, vale la pena ser emprendido dado que permite nuevamente la reflexión sobre el Estado Moderno en Chile y esclarece qué referentes intelectuales o ideológicos se podrían haber tenido en aquella época en que un grupo de ilustrados optó por el Estado republicano, que es a fin de cuenta, lo que celebramos en 2010.

Fue justamente este profesor de la primera cátedra de Derecho Natural en Europa (Universidad de Heidelberg 1661-1668), quien ha sido nombrado como el fundador de un derecho natural moderno apoyado en la razón humana y no en la revelación divina (cristiana) ${ }^{8}$. Aunque de forma muy breve, esta denominada secularización del Derecho Natural, fue uno de sus grandes logros y herencia para el mundo moderno, al sentar el primer ataque efectivo al predominio de la escolástica como filosofía social de la época ${ }^{9}$. Necesariamente, Pufendorf no representa un ícono de la República, ni tampoco se muestra como defensor de la Democracia o la soberanía popular. Pufendorf fue un teórico del absolutismo político, vivió bajo el amparo de una de las monarquías absolutas más fuertes e importantes del siglo XVII como la de Karl XI, en Suecia, y por último criticó tal como un cientista político en la actualidad, las formas de gobierno de su presente y especialmente un sistema político imperial que el mismo denominó mounstro simile ${ }^{10}$. Seguramente por el desconocimiento biográfico que en su misma época existió sobre su persona, y como en muchos otros casos de la historia del pensamiento político, la obra de Pufendorf resultó ser tanto o más importante un siglo después en el contexto intelec-

7 En el debate periodístico aparecen Pufendorf, Grocio, Locke, Maquiavelo en la sátira del Hambriento aparecida en la sección "Marítima " del Mercurio de Valparaíso. Collier, Simon. op cit. (n.6), p. 171.

8 “Trotzdem liegt hier der Grund zu Pufendorfs späteren Werken: die Erkenntnis der sozialen und sittlichen Welt als spezifisch >>autonomen<< menschlichem Wirkungsraum. Er leugnete zwar nicht seine Abhängigkeit vom Willen Gottes und von den Gesetzen der Natur, aber er wusste um seine Eigenständigkeit”. Wolf, Erik. Grosse Rechtdenker der deutschen Geistesgeschichte. Tübinge, Alemania: Editorial J. C. B. Mohr, 1951, p. 316.

9 "Hence it is that the Dictates of the Law of Nature are adapted Only to Human Judicature, which does not extend it self beyond this Life; and it would be absurd in many respects to apply them to the Divine Forum, which concerns itself Only about Theology". PufEndorf, Samuel. "The whole duty of man, according to the law of nature". Edición al inglés de Ian Hunter y David Saunders, Liberty Fund, Indianapolis, 2003, Prefacio, p. 20.

10 Pufendorf, Samuel. La Constitución del Imperio Alemán 1667. Traducción y Estudio Preliminar Marco Hueste. Valparaíso, Chile: Edit. Edeval, 2009. Otra perspectiva de esta famosa afirmación en: Whaley, Joachim. A Tolerant Society?, Religious Toleration in the Holy Roman Empire. En: Grell, Ole Peter, Porter, Roy. (Edits). Toleration in Enlightenment Europe. Cambridge, Inglaterra: Cambridge University Press, 2000, p. 177. 
tual de época de revoluciones modernas (Inglaterra, EEUU, Francia), que en el debate alemán del siglo XVII sobre la naturaleza del Derecho Público que el mismo inició tras la publicación de su obra Die Verfassung des Deutschen Rechts $1667^{11}$.

La importancia de la presencia de sus obras en el contexto ilustrado, recaía en la formulación de ideas más profundas y estructurales con respecto a la forma de pensar y organizar racional e institucionalmente el poder político de forma sistemática y no tanto en ideas liberales que encendieran el clima revolucionario en vísperas de la Revolución. A pesar de las diferencias en el lenguaje político ilustrado del XVIII y la radicalización del discurso iusnaturalista moderno -del que era su fundador-, la obra de Pufendorf tenía un especial significado. Seguramente fue el sentido sistemático de su obra, por el cual tantas traducciones y comentarios acerca de Iure Naturae Gentium y Officio Hominis aparecieron en época de ilustración francesa y sirvieron en muchos casos de referente teórico para reformulaciones sobre un orden político secular. Aquí recae gran parte de su originalidad ${ }^{12}$.

Pufendorf limpió de las raíces escolásticas el Derecho Natural de la época e indicó con precisión los límites que correspondían específicamente a lo político o sociedad civil. El ámbito político era para el jurista alemán el ámbito de la ley natural entendida como razón ${ }^{13}$. Es decir, un Derecho Natural ya no justificando el orden moral trascendente cristiano escolástico, sino, apoyando y justificando un orden político secular, cuya máxima representación es el Estado soberano que es en sí una persona moral, tal como lo ha descrito últimamente Quentin Skinner ${ }^{14}$.

Pero no solo en el período de la emancipación se encuentran presentes los clásicos del Derecho Natural Moderno, también para el tiempo de reformas borbónicas en época colonial, las universidades hispanoamericanas habrían tenido presente en sus mallas curriculares algunas de estas obras iusnaturalistas como ha demostrado el estudio clásico de Mario Góngora (1975). En efecto, la introducción de la racionalidad científica e ilustrada y algunos principios modernos de organización política y económica por parte de los borbones desde aproximadamente 1770 en adelante, generó, según Góngora, un progresivo desapego de la escolástica como línea rectora del universo intelectual colonial, cuyos referentes máximos eran el Derecho Romano, el

11 Huesbe Llanos, Marco A. op cit. (n.5). "Sin duda, la influencia de Pufendorf fue significativa para elaboración de los trabajos preliminares del allgemeine Landerecht de Prusia e influyó también en el Bürgerliche Gesetzbuch de Austria y en el proceso de emancipación de las Indias en la América Hispana”.

12 Mientras que José Antonio de Rojas habría sido el primero en conseguir las obras de Pufendorf, Eyzaguirre indica que Manuel de Salas trajo desde Espańa la obra de Pufendorf “Introducción a la historia general y política del universo", la cual aparecía en el Index por sus ataques a la colonización de la Corona. Sumado a los juristas Miguel de Eyzaguirre, Fernando Márquez de la Plata -este último vocal en la primera junta de gobierno- y José Martínez de Rozas. Eyzaguirre, Jaime. op cit. (n.6), pp. 7273.

13 Hochstrasser, Tim. Natural Law Theories in the Early Enlightenment. Cambridge, Inglaterra: Cambridge University Press, 2000, p. 69. Wieacker, Franz. Historia del Derecho Privado en la época Moderna. Madrid, Espańa: Editorial Aguilar, 1957, p. 13.

14 Skinner, Quentin. "Una genealogía del Estado Moderno", en: Estudios Públicos, No 118, 2010, pp. 31 y ss. Santiago, Chile: Centro de Estudios Públicos. 
Derecho Canónico, la Teología, Filosofía Escolástica y, en el caso que nos preocupa, la Teoría del Derecho Divino de los Reyes. En esta etapa, conceptualizada no sin reparos como Despotismo Ilustrado, se sustituyó en el ámbito cultural iberoamericano el aristotelismo como fundamento filosófico, el espíritu unitario del Barroco, y el sentido misional e ideológico de la Monarquía como tutora de la Contrarreforma ${ }^{15}$. Las ciencias prácticas, la racionalización de la economía y el Estado, así como la mirada científica del mundo se abrían paso ya sea de manera oficial o encubierta ${ }^{16}$.

La influencia de la filosofía de las luces se mezclaba con el antiguo sistema escolástico de explicación de la realidad y en su conjunto eran parte central de la cultura colonial eclesiásti$\mathrm{ca}^{17}$. Este era el contexto intelectual de los círculos ilustrados españoles y también criollos que se sentían, aunque no de forma íntegra, parte también de la órbita ilustrada europea pero bajo las sabidas condicionantes y limitaciones impuestas por la Monarquía borbónica ${ }^{18}$. En su reforma a los currículos académicos de las universidades coloniales a favor de las ciencias prácticas y con el fin de mejorar la económica, sociedad y Estado (administración), las ideas modernas ilustradas llegaron inevitablemente en su dimensión más pura y de forma más rupturista que en España. En tal proceso modernizante, afirma Góngora, los libros franceses no fueron la única fuente del pensamiento ilustrado moderno (Mabillon, Traité des Etudes Monastiques, Rollin, Fleury). Un papel fundamental juega también Feijoó y otros autores como el portugués Luis Antonio Verney o Barbadinho. En este sentido, una de las obras más ampliamente leídas a fines de la época colonial y que puede ser considerada uno de los elementos más discordantes ante la rígida cultura eclesiástica de la Colonia, fue la Historia del Derecho Natural y de Gentes del profesor del Colegio Real de San Isidro de Madrid, Joaquín Marín y Mendoza. Su enseñanza fue censurada y puesta bajo amenaza de propaganda revolucionaria, seguramente porque resultó ser una famosa síntesis, en el ámbito del ius gentium, de las tesis modernas de Grocio, Pufendorf, Thomasius y Heinecius.

Tal obra, contribuyó a desarrollar -relata Góngora- una nueva mentalidad entre los juristas locales, los cuales pudieron apoyar sus teorías en un nuevo paradigma distinto al basado en el antiguo Derecho Natural, el Derecho Romano y la Escolástica ${ }^{19}$. Es más, las nuevas cátedras de derecho natural de las universidades hispanoamericanas, que de forma ecléctica y parcial enseñaban el ius gentium, desplazaron a las de Derecho Canónico y siguieron los principios de Pufendorf, Wolf y Heinecius a través de la mencionada obra de Marín y Mendoza. Según Góngora, esta cátedra habría influenciado a la generación que afrontó los estragos de la Independen-

15 Huesbe, Marco (comp.). Arte y Política del Barroco. Valparaíso, Chile: Editorial Universitarias de Valparaíso, 2000.

16 Defourneaux, Marcelin. Inquisición y censura de libros en la España del siglo XVIII. Madrid, España: Editorial Taurus, 1973, p. 44.

17 Críticas a tal sistema por parte de los criollos en: VillaLobos, Sergio. op cit. (n.1). p. 68.

18 Góngora, Mario. op cit. (n.6), p. 179.

19 Ibid., p. 183. 
cia, hecho que se corrobora porque debió soportar los ataques de la Corona. Se acusaba que este tipo de cátedra funcionaba como medio para la propagación de ideas políticas peligrosas, hasta que por tal motivo, fue suprimida en los años siguientes a la Revolución Francesa ${ }^{20}$.

Las tesis de Pufendorf y otros juristas del iusnaturalismo moderno protestante fueron parte de la formación académica de los hombres que debieron afrontar las coyunturas políticomilitares desatadas por Napoleón en España, y también como referente teórico para una nueva interpretación de las ideas contractualistas junto con Rousseau y los filósofos franceses. Pensamos que la enseñanza de tales tesis iusnaturalistas modernas como parte de las reformas curriculares académicas en época del Despotismo Ilustrado, tienen cierto sustento por el sentido práctico y ecléctico que tenían las propuestas de Pufendorf, quien a fin de cuenta como hemos señalado, era un teórico también del absolutismo como lo ha indicado Huesbe $(2008)^{21}$.

Su nueva sistematización del Derecho Natural representa por primera vez un sistema cerrado de sus fundamentos en Alemania y debió ser de enorme influencia y seducción para el mundo borbónico al sustentar un Derecho Natural Social, es decir, y en contraposición a lo que serán las posturas radicales pactistas en Francia un siglo después, Pufendorf no cree en un derecho subjetivo centrado en el individuo como principio y último fundamento del sistema político y social, sino en una doctrina de deberes cuyas obligaciones deben observar todos los hombres en su conjunto a fin de llevar una vida social segura, tolerante y feliz ${ }^{22}$. Una idea muy cercana al sentido espiritual unitario del barroco y por tal, a pesar de la escaza difusión directa y alta censura de las obras de Pufendorf en España ${ }^{23}$ podría perfectamente, según Jocelyn-Holt, haber tenido cabida en la nueva concepción racionalista, voluntarista y modernista de Estado que las reformas ilustradas borbónicas pretendían sobre el Estado Moderno en la península ${ }^{24}$. H. E. Bödeker sostiene que el Estado para el historiador alemán es una institución secularizada y que la civitas no es una societas perfectísima, donde es posible actuar conforme a la naturaleza racional del hombre y lograr una vida plena y querida por Dios. Pufendorf, según Bödeker, reduce al Estado a una instancia que debe resguardar los mínimos requerimientos de la sociabilidad, justicia, equidad y el derecho ${ }^{25}$.

20 Ibid., p. 192.

21 Huesbe Llanos, Marco. Teoría, Administración y Participación en el Estado Moderno. Bodino, Arnisaeus, Beza. Valparaíso, Chile: Ediciones Universitarias de Valparaíso, 2008, p. 37. Una sistematización del pensamiento político moderno alemán en: Carvajal, Patricio. La Crisis del Estado Moderno. La Staatslehre europea de Martin Luther a Petra Kelly. Valparaíso, Chile: Ediciones Facultad de Humanidades Universidad de Playa Ancha, 2010, p.46.

22 Huesbe Llanos, Marco A. La teoría política...(n.5).

23 Rus Rufino, Samuel. Estudio Preliminar. En: Pufendorf, Samuel. De los deberes del Hombre y del Ciudadano en Dos Libros. -2a edición en espańol- Traducción Samuel Rus Rufino, Madrid, España: Editorial Estudios Constitucionales, 2002.

24 Jocelyn-Holt, Alfredo, op cit. (n.6), p. 107.

25 Van Gelderen, Martin y Skinner, Quentin. Republicanism: Republicanism and constitutionalism in early modern Europe. Cambridge, Inglaterra: Cambridge University Press, 2002, p. 229 y ss. En efecto, en reiteradas ocaciones Pufendorf menciona: "If we trace that Original of Civil Societies or Commonwealths, it is evident, that Men having found the Inconveniencies and Dangers which a tended a solitary Life in the free natural State, did enter und unite themselves into Societies for their Com- 
Como se tiende a creer, los bullados conceptos de soberanía popular y pacto social fueron elementos propios del pensamiento político liberal que encendieron los ánimos revolucionarios en EEUU, Francia y también en América Latina ${ }^{26}$. Sin embargo, como ha mostrado Stuven, el concepto de derechos individuales no fue ni siquiera luego de la Independencia "la base del canon del dialogo social" 27 , porque en los inicios de la República los referentes ideológicos modernos convivían con las prácticas y pensamientos tradicionales sobre el orden social.

Los conceptos de contrato social, pacto social, estado de naturaleza y derechos fundamentales, presentes en el pensamiento francés y recepcionados en el debate principalmente periodístico en Chile, fueron consecuencia de una evolución y reinterpretación del discurso iusnaturalista moderno preservado por Grocio y Pufendorf ${ }^{28}$; Reformulación principalmente protestante, por tal censurada, en la cual también el jurista sajón juega un rol fundamental al contraponerse a las interpretaciones neo-escolásticas de la escuela de Salamanca (Suárez; F. Doctrina populista $)^{29}$. En esta vereda opuesta, para ejemplificar la diversidad historiográfica sobre el tema, se encuentra Jaime Eyzaguirre, quien suma la presencia de estas obras ilustradas a un proceso mayor y de larga gestación que estaba arraigado en el espíritu municipal español. El pensamiento reformado borbón, idealizado por las tesis más conservadoras sobre el período, se detiene tan sesgadamente como su par liberal en puntos clave del desarrollo cultural de España durante el siglo XVII y XVIII como fueron la Escuela de Salamanca, pensamiento de Francisco de Suárez, el Despotismo Ilustrado de los Borbones, Cortes de Cádiz, Constitución Liberal de 1808, Doctrina populista, etc. ${ }^{30}$ Creemos que las corrientes de pensamiento tanto francesa ilustrada como tradicional hispánica en el ámbito del pensamiento y las ideas políticas en Chile

mon Security: And having agreed to a certain Form of Government, did constitute one certain Person, or a Counsel, who were to be a supreme Governous of that Society; unto whom they submitted themselves and their fortunes, for the common Benefit of that Society". Pufendorf, Samuel. The nature and qualification of religion in reference to civil society. Traducción al Ingles Jodcus Crull, Edición Simone Zurbuchen, Indianápolis, Estados Unidos: Editorial: Liberty Fund, 2002, p. 67.

26 Jellenik, Georg et al. Orígenes de la Declaración de los Derechos del Hombre y el Ciudadano. Traducción Adolfo Posada, Madrid, España: Editorial Nacional, 1984. Augat, Daniel. Die Aufnahme der Lehren Samuel von Pufendorfs (1632-1694) in das Recht Vereinigten Staaten von Amerika. Colonia, Alemania, 1958. "So konnte ich zeigen, dass Samuel Pufendorf in der damals noch englischen Kolonie Nordamerika einen begeisterten Anhänger in John Wise (1652 bis 1725) gefunden hatte, der durch seine in engster Anlehnung an Pufendorf verfassten Teile seiner kirchenpolitischen Schriften nicht nur für die Demokratisierung der kirchenrechtlichen Verhältnisse, sondern auch für die amerikanische Unabhängigkeitsbewegung und die Erklärung der Menschenrechte von erheblichem Einfluss war". Welzel, Hans. Die Naturrechtslehre Samuel Pufendorfs: ein Beitrag zur Ideengeschichte d. 17. u. 18. Jh. -2a a edición- Berlin, Alemania: Editorial de Gruyter, 1986, p. 3.

27 Stuven, Ana María. op cit. (n.2), p. 35.

28 Gierke, Otto. Natural Law and the Theory of Society1500 to 1800. -1 a edición al inglés-, Traducción e Introducción Ernest Barker, Boston, EEUU: Editorial Beacon Press, 1960, p. 155.

29 Carpintero Benítez, F. Del Derecho Natura Medieval al Derecho Natural Moderno: Fernando Vázquez de Menchaca. Salamanca, Espańa: Ediciones Universidad de Salamanca, 1997, p. 264.

30 Eyzaguirre, Jaime. op cit. (n.6), pp. 71 y ss. 
han olvidado, o simplemente opacado, la presencia y tal vez influencia del pensamiento iusnaturalista alemán representado por Samuel Pufendorf o el utilitarismo inglés de Bentham y el círculo del Edinburg Review en que participó Andrés Bello ${ }^{31}$.

La importancia y fama de Iure Naturae Gentium (1672), de Samuel Pufendorf, radica también en que ayudó a difundir en el conteniente europeo las ideas propuestas por Hobbes en la década de 1660 en Inglaterra. Precisamente, ambos autores compartían la idea moderna de "Persona Moral", cuyo principio político fundamental heredado a la Ilustración era que el Estado es el resultado de la unión de la sociedad en una persona moral que es soberana ${ }^{32}$. La obra de Pufendorf mencionada ayudó, a su vez, a difundir entre sus comentadores y traductores en el siglo XVIII y XIX las ideas de Grocio $^{33}$ y también de su maestro en Jena, el cartesiano E. Weigel $^{34}$. El discurso iusnaturalista protestante se fue nutriendo en el siglo XVI y XVII de su propia y dura experiencia histórica, marcada por las persecuciones, cacerías, inquisición y censura del Imperio Cristiano Español y la Iglesia Romana ${ }^{35}$. El lenguaje político relativo a la organización del Estado Moderno y a la sociedad civil, entendida como un espacio moral entre gobernados y gobernantes, adquirió en este debate de mutuas influencias y "resignificaciones" una continuidad hasta nuestro presente gracias a las múltiples traducciones, la acción de un mercado cada vez mayor de tráfico y circulación de libros, incluso censurados, y también por supuesto por la misma sociabilización del lenguaje político, ya sea en el ámbito académico universitario como al interior de logias y cofradías ${ }^{36}$. Por ello, insistimos en que, tan importante como la formulación de las ideas de Grocio, Hobbes y Pufendorf sobre el ius gentium, fueron también las traducciones de sus obras al ámbito intelectual francés durante el siglo XVIII en víspera de la Ilustración ${ }^{37}$.

31 Stuven, Ana María. op cit. (n.2), p. 70.

32 "Por lo que el Estado se define como persona moral compuesta, cuya voluntad, implícita y unida a partir de los pactos de muchos, se considera voluntad de todos, para que pueda servir junto con los recursos y capacidades de todos para la paz y seguridad común”. Pufendorf, Samuel., De los deberes del Hombre... op. cit (n.23), Lib. II, Cap. VI, 10. p. 126. Décadas más tarde Rousseau dirá: "Este acto de asociación produce un cuerpo moral y colectivo, compuesto de tantos miembros como votos tiene la asamblea, la cual, por este mismo acto, recibe su unidad, su yo común, su vida y su voluntad”. RoussEAU, Jean. Jacques. El Contrato Social. Trad. Madrid, España: Editorial Alba, Libro I, Cáp. IV, 1998, p. 34. "El deseo acreditado de la libertad; la disposición generosa de sacrificar su interés personal al interés universal del pueblo en el momento en que se constituye un hombre legislador por el voto y la confianza de sus ciudadanos, deja de existir por sí mismo, y no tiene más familia que la gran asociación del Estado". Henríquez, Camilo. Proclama de Quirino Lemachez. En: Henríquez, Camilo y Martínez de Rozas. Páginas de la independencia nacional. <en línea> Santiago, Chile: Editorial del Pacífico, Instituto de Estudios Políticos, 1976. Disponible en la World Wide Web: <http://www.memoriachilena.cl/temas/documento_detalle.asp?id=MC0001691>

34 WolfF, Erik. op cit. (n.8), p. 316.

35 Institut für Europäische Geschichte IEG Disponible en la World Wide Web: <http://www.ieg-mainz.de/likecms/index. php?site $=$ site. $h$ tm \&dir $=\&$ nav $=168>$

36 Skinner, Quentin. La Libertad antes del Liberalismo. -2a edición- Trad. Fernando Escalante, Madrid, España: Ed. Taurus, 2004, p.67. Véase, Castillo, Vasco. op cit. (n.4).

37 Darnton. Robert. Los best sellers prohibidos en Francia antes de la revolución. Buenos Aires, Argentina: Fondo de Cultura económica, 2008. Burke, Peter y Briggs, Asa. Historia Social del Conocimiento. De Gutenberg a Internet. México DF, México, 
En el siglo XVIII fue Jean Barbeyrac el traductor más importante e influyente de Pufendorf con Le droit de la nature et des gens $1706^{38}$. En lo central: "Si bien Barbeyrac critica tanto a Hobbes como a Pufendorf, su traducción dio mayor difusión al argumento según el cual la unión que crea las asociaciones civiles se forma cuando un número de individuos se consolida en una sola Personne Morale, y que el nombre de esta Personne es l'Etat' 39 . R. Tuck comenta que fue el trabajo de Barbeyrac quien dio a conocer al público europeo durante el siglo XVIII la teoría de la ley natural protestante, mediante la traducción y estudio de De Iure Belli ac Pacis de Grocio y, en 1706, de De Iure Naturae et gentium de Pufendorf. La Ilustración conoció numerosas traducciones de estas fuentes a todo tipo de idiomas (De Iure Belli tenía a comienzos del siglo XVIII veintiséis ediciones), logrando una relevancia para el debate político y moral de la época de las revoluciones sin igual ${ }^{40}$. No es de extrañar por tanto que P. Hazard se detenga con atención en el título de la obra Officio Hominis de Pufendorf: "El deber del hombre y del ciudadano: ¡cómo nos sorprende el título en esta fecha; Parece anticipado a un centenar de ańos, por lo menos; si se nos hubiera preguntado a qué época pertenece, lo hubiéramos atribuido sin dudas al vocabulario de la Revolución Francesa" ${ }^{41}$. Dada esta gran difusión y masificación de sus escritos, no es raro que en sus numerosos y costosos viajes a Europa, como relata Collier, Manuel de Salas o José Antonio de Rojas hayan adquirido su obra junto a otros clásicos de la Ilustración ${ }^{42}$.

Fueron sus aportes científicos al ámbito jurídico y moral por los cuales Pufendorf, según Bödeker, se convirtió a fines del siglo XVII en un best seller internacional ${ }^{43}$, desatando vívidos debates un siglo después en el ámbito de la moral y contribuyendo a crear una nueva metodología en la filosofía moral alemana según Hochstrasser: el escepticismo ${ }^{44}$. También en el plano jurídico su aporte al Derecho Público Alemán y la Ciencia Política del siglo XVIII con su particular estudio ya mencionado Die Verfassung des Deutschen Reiches $1667^{45}$. Weizel agrega

Edit. Taurus, 2007. Chartier, Roger. Espacio público, crítica y desacralización en el siglo XVIII: los orígenes culturales de la Revolución francesa. Barcelona. Espańa: Editorial Gedisa 1995.

38 Relación de Barbeyrac y su recepción de la obra de Pufendorf en: Hunter, Ian y Saunders David, Prefacio. En: Pufendorf, Samuel. The whole duty of man, according... (n.9), p. XV.

39 SkINner, Quentin. Una genealogía... (n. 14), p. 34.

40 "The notes to these editions keyed their texts into all the relevant discussions of natural law from antiquity down to the 1720s, and the two Works together quickly became the equivalent of an encyclopedia of moral and political thought for Enlightment Europe”. Tuck, Richard. Introduction. En: Grotius, H. The Rights of War and Peace. Indianapolis, Estados Unidos: Editorial Liberty Fund, 2005, p. xi.

41 Hazard, Paul. La Crisis de la Conciencia Europea. Madrid, España: Editorial Pegaso, 1974, p. 238.

42 Collier, Simon. op cit. (n.6), p. 169.

43 "It was the Challenger to unite the norms of ethics and law into a scientia, into 'synthetic'and deductive system". En: VAN Gelderen, Martin y Skinner, Quentin. op cit. (n.25), p. 229.

44 Hochstrasser, Tim. op. cit. (n.13), p. ix- xiii.

45 "Pufendorfs Wirkungen sind vielfältig, und sie reichen mindestens bis in das ausgehende 18. Jahrhundert. Von der lebhalten Debatte um die Verfassungsschrift von 1667 war bereits die Rede, Auf dem Gebiet des Naturrechts ist er in Deutschland und in Europa für hundert Jahre die grosse Autorität"Stolleis, Michael. Geschichte des öffentlichen Rechts in Deutschland. München, Alemania: Editorial Verlag C. H. Beck, 1988, p. 284. Pufendorf, Samuel. La Constitución del Imperio Alemán 1667... (n.10). 
el dato que ediciones de Barbeyrac al francés de De Officio hominis aparecen en París en fechas tan lejanas como 1820, 1822 y 1830. Incluso ediciones al ruso a cargo de Katarina II y Pedro el Grande reconocieron también su contribución ${ }^{46}$. Conceptos fundamentales del pensamiento político moderno como el de voluntad general ${ }^{47}$ de Rousseau tendría su antecedente en el discurso político de Pufendorf como lo ha planteado Gierke y fueron los mismos iluministas quienes en el siglo de las luces reconocieron a Pufendorf como fundamental en la nueva visión de Estado ${ }^{48}$.

Fue tan potente la circulación de este tipo de ideas que, partiendo de la obra de Pufendorf, el jurista suizo E. Vattel difundió con éxito a su vez la idea en Inglaterra y Francia de que la sociedad es la portadora original de la soberanía siendo representada en el tiempo por soberanos (monarquía o democracia) que miran por el bien común y la seguridad del Estado. De esta forma se entendía como legítimo el poder del rey o asamblea y en cualquier otra instancia en que no se distinga claramente la persona del Estado de su representante (el gran principio impulsado por Hobbes) ${ }^{49}$, el poder político y la obligación política de los súbditos o ciudadanos es inválida ${ }^{50}$. Fue el mismo Emer de Vattel quien llamó la atención de uno de los mayores humanistas americanos: Andrés Bello. En efecto, en sus Principios de Derecho Internacional, publicado en Valparaíso en 1834, Bello dedica un apartado especial a las fuentes del Derecho Natural y de Gentes, reconociendo la autoridad de los clásicos europeos de esta materia y sobre los cuales sustentaba su tratado" . De esta forma indica: "Vattel es el escritor más elegante y popular de esta ciencia y su autoridad se ha mirado tiempo ha como la primera de todas. Su obra ha sido citada con respeto en los juzgados de almirantazgo, donde se ventilan causas que conciernen a

46 Welzel, Hans. op cit. (n.26), p. 2.

47 La misma idea aparece en el discurso de Manuel de Salas en el Primer Congreso Nacional de 1811: "la facultad de gobernar es y debe ser el resultado de la voluntad de los que depisitan en otro una parte de su libertad y fortuna para que con seguridad les conserve las demás y aquél o aquéllos en que se depone la suprema autoridad, la reciben primero del completo o extracto de las voluntades de todos". Stuven, Ana María. op cit. (n.2), p. 33.

48 "Trotz aller Polemik zeigt Rousseau eine offensichtliche Vorliebe für Pufendorf. Derathé bringt weitere Belegefür die Hochschätzung und den Einfluss Pufendorfs im 18. Jahrhundert, z.B. bei Diderot (Encyclopädie)”. Welzel, Hans. op cit (n.26), p.3.

49 SkInner ,Quentin. Visions of Politics, Vol III, Hobbes and Civil Science. Cambridge, Inglaterra: Cambridge University Press, 2005, p.13. Bödeker, Hans. E. En: van Gelderen, Martin y Skinner, Quentin. op cit. (n.25), p. 228.

50 "Como Pufendorf, Vattel concluye ofreciendo una visión del estado no sólo desde la perspectiva de un garante de la legitimidad de la acción gubernamental, sino de su poder para que naciones enteras queden vinculadas a sus promesas por largos períodos de tiempo”. Skinner, Quentin. Una genealogía... (n.14), p. 38.

51 "No hay un código en que estén recopilados los preceptos y prohibiciones del Derecho internacional, sea natural, sea instituido; lo que produce incertidumbres y dudas, que los Estados poderosos no dejan nunca de interpretar a su favor. A falta de este código se recurre ordinariamente a las obras de los autores más acreditados de jurisprudencia internacional, como son Grocio, Wicquefort, Puffendorf, Barbeyrac, Bynkersckoek, Burlamaqui, Wolfio, Valin, Vattel, Emerigon, Azuni, Pothier, Martens, Pardessus y otros. En algunos puntos no es uniforme su doctrina; pero donde los principales escritores están de acuerdo, hay una fortísima presunción a favor de la solidez de sus máximas, y ninguna potencia civilizada se atreverá a despreciarlas, si no tiene la arrogancia de sobreponerse al juicio del género humano; de lo que a la verdad no han faltado ejemplos en los últimos siglos y en la parte más culta de Europa”. Bello, Andrés. Principios de derecho internacional. Buenos Aires, Argentina: Edit. Atalaya, 1946, vol. IV, p. 139. 
esta clase de jurisprudencia, en los debates de las asambleas legislativas y en las negociaciones diplomáticas". Pero Vattel -dice un autor moderno- carece de precisión filosófica. Sus discusiones son a menudo vagas y a veces fastidiosamente difusas. Después de todo, no hay obra alguna que dé nociones exactas del Derecho de gentes natural e instituido y cuyas máximas se hallen suficientemente apoyadas en argumentos, autoridades y ejemplos. De la edad de Grocio a la nuestra ha crecido considerablemente el código de la guerra; sus leyes se han fijado con exactitud y se han mitigado en gran parte ${ }^{52}$. Andrés Bello comparte en estos pasajes el sentimiento común entre algunos ilustrados de la época e interpretó el Derecho Natural y de Gentes como remedio a los principios de la Realpolitik del sistema internacional de estados o Sistema Westfaliano dominado por los conceptos de interés, necesidad y equilibrio de poder ${ }^{53}$.

Los clásicos de la Ilustración y la Ley Natural fueron parte importante de la llamada historia de la moralidad ${ }^{4}$, ya sea en la desmitificación del ámbito civil y la organización del Estado (Hobbes, Pufendorf, Barbeyrac) ya en el plano externo de las relaciones exteriores entre los Estados (Grocio, Vattel, Kant). Pero la relevancia de Pufendorf para la posteridad reside, principalmente, en la exitosa separación entre el pensamiento revelado y la razón natural, entre la naturaleza en sentido material (entia physica) y el ineficaz conocimiento social (entia moralis); estos avances son para Stolleis, un signo de que Pufendorf alcanza un sentido plenamente moderno en su pensamiento. Por ello, también Denzer, no deja de resaltar su pasión por la exactitud del conocimiento y el método, la sustitución de la religión por medio de un enfoque filosófico del mundo inmanente, la diferencia entre el saber demostrable y fáctico y, por último, su afán hacia una unidad sistemática ${ }^{55}$. Grocio, Hobbes y Pufendorf fueron los clásicos de la ley natural moderna y sus obras fueron reconocidas -incluso a regańadientes- tanto como por sus contemporáneos como sus seguidores en el siglo XVIII y XIX ${ }^{56}$.

El renovado interés por las obras del jurista sajón se debe no solo a la originalidad de sus planteamientos, sino aún más, por la mencionada influencia de sus escritos, a la masificación de sus comentaristas y traductores en época de ilustración como referente teórico para la justifica-

52 Ibid., p. 138.

53 Una precisión conceptual en: Oro Tapia, Luis. "Notas sobre el equilibrio de poder", en: Revista Enfoques, No 12, Vol. VII, Universidad Central, Santiago, Chile, 2010.

54 Hochstrasser, Tim. op. cit. (n 13), p. xii.

55 "Die Leidenschaft für Exaktheit des Wissens und der Methode, die Ersetzung des Theologischen durch den weltimmanenten Ansatz der Philosophie, die Unterscheidung zwischen beweisbarem und faktischem Wissen, das Streben nach systematischer Einheit”. Denzer, Horst, citado por Stolleis Michael. op. cit. (n.43), p. 283.

56 Leibniz, Gottfried Wilhelm. "Algunas observaciones sobre las ideas fundamentales", de Samuel Pufendorf, dirigidas a G. W. Molano. En su: Escritos de Filosofía Jurídica y Política. Madrid, España: Editorial: Fondo Cultura Económica. 2001, p. 168. Se conoce como Specimen controversiarum a la disputa intelectual que enfrentó a Pufendorf y V. Alberti y otros teóricos luego de la publicación de De Iuri natura et Gentium (1672). Alberti, profesor en Leipzig, escribió De iuri naturae compendium 1676, obra con la que apoyó fuertemente a los ortodoxos luteranos y la síntesis aristotélicas y el argumento de la voluntad divina como origen del Derecho Natural. Pufendorf atacó la imposición divina, aplicada según él, a la existencia pre-estatal, considerando por sobre ello el instinto de sociabilidad humana y su cálculo de la racionalidad de la vida social como el mejor estado para la propia conservación. Vs. Hochstrasser, Tim. op. cit. (n.13), p. 69. 
ción y legitimidad de nuevas formas de gobierno moderna. Recientemente, en este sentido, la editorial Liberty Fund ha publicado las traducciones inglesas de Pufendorf aparecidas en época de transición del absolutismo al parlamentarismo inglés, haciendo hincapié a los conceptos republicanos de su pensamiento, seguramente útiles en el debate político de la época. Ejemplo de ello es la primera traducción al inglés de su compendio De Officio Hominis, publicado en 1691 por un profesor de geometría de Greshman College: Andrew Tooke (1673-1732). Ediciones anónimas inglesas de 1716 y 1735 volvieron a poner en relieve tales conceptos parlamentaristas, incluyendo notas a pie de páginas e importantes comentarios que J. Barbeyrac, en 1707, había hecho a la edición francesa de tal fuente. Los comentaristas ingleses resaltaban que Pufendorf no opta por ninguna forma de gobierno en particular en sus escritos políticos. En realidad, esto quería decir que no mostrando favoritismo por el régimen monárquico, Pufendorf también era promotor de las formas parlamentaristas y democráticas de gobierno. Esta opinión está más explícita en el médico oriundo de Hamburgo Jodocus Crull, experto traductor al inglés de las obras de Pufendorf ${ }^{57}$. En la dedicatoria de $O f$ The nature and qualification of religion, dirigida al honorable William Lord Craven, Crull indica que en el centro de la felicidad de la sociedad civil está la adopción de la forma democrática de gobierno, donde el poder de la soberanía no fuese ilimitado, como lo sostenían "Mr. Hobbes's Mounstrous Principles" 58 . Según Crull, en este tratado de Pufendorf, la palabra Princeps o Prince son sinónimos para el autor y es claro: "That he attributes the Sovereign Power not always to one single Person, but sometimes also to a Council invested with the Supreme Administration of the Sovereign Authority in the Commonwealth" ${ }^{\text {59. Reitera }}$ Crull, el cuidado que debe tenerse de que bajo la pretensión de mantener las prerrogativas del Príncipe, no se respete ni la libertad ni la Propiedad sobre los cuales se construye el consenso común de la mutua defensa contra la violencia ${ }^{60}$. De esta manera el nombre de Pufendorf alcanzó bastante fama gracias a numerosas interpretaciones (parlamentarias o democráticas), aun cuando estás no fuesen totalmente correctas o ajustadas a su real pensamiento. Lo importante fue que su obra se entendió en el siglo XVIII y comienzos del XIX como parte fundamental del cuerpo de obras clásicas de la Ilustración y del proyecto moderno occidental de organización política (Republicanismo- Democracia) que siguió nuestra elite política.

La preponderancia de la literatura francesa ilustrada dentro de las ideas políticas durante el siglo XVIII y XIX en Chile, si es que realmente tuvieron algún lugar en la toma de decisiones, olvida que sus planteamientos más originales están ya presentes en el siglo XVII, precisamente en el contexto denominado de pre-Ilustración e iusnaturalismo moderno ${ }^{61}$. En tal escenario, mucho más preponderante para la modernidad parece ser el discurso político

\footnotetext{
Zurbuchen, Simon, Introducción. En: Pufendorf, Samuel. Of The nature and qualification... (n.25). p. xvii.

Crull, Jodocus. En: Pufendorf, Samuel. Of The nature and qualification of religion.... (n. 25), p.4.

Ibid.

Ibid. p.5.

1 Geyer, Bodo y Goerlich, Helmut (compil.). Samuel Pufendorf und seine wirkungen bis auf die heutige zeit. Alemania, BadenBaden: Nomos; 1996.
} 
iusnaturalista protestante, desarrollado en Alemania, Holanda e Inglaterra por juristas como Grocio, Hobbes y Pufendorf. Una de las ideas políticas más significativas elaboradas tras el largo debate académico de publicistas y teóricos iusnaturalistas protestantes fue clarificar el origen del poder político, desmitificarlo de la segunda escolástica y limitar un ámbito autónomo de su ejercicio ${ }^{62}$. Ha sido Jocelyn-Holt quien ha ido más lejos en la interpretación y rescata esta nueva moderna visión del Estado recepcionada en época de reformas borbónicas posiblemente apoyadas en la obra e influencia pufendoreana ${ }^{63}$.

Esta visión del ámbito y la organización política moderna elaborada por Pufendorf tiende a tratar más sobre una nueva estructura política secular y racional que respondía a los desafíos de multiconfesionalidad y tolerancia religiosa tras la Guerra Civil Religiosa Europea, que a una forma de gobierno de preferencia como lo era la democracia y la República en vísperas de la Revolución Francesa. Esta herencia del iusnaturalismo protestante podría llegar a ser un poco más valorada, a la luz de nuestros 200 años de existencia, al momento de referirse a las ideas revolucionarias francesas de enorme revuelo y sentido confrontacional que despertaron los ánimos revolucionarios en algunos personajes, pero que no necesariamente tuvieron aplicación en la práctica política o institucional. En un proyecto moderno impuesto por la elite sobre el orden social mestizo-indígena y sobre el pensamiento tradicional hispánico es bueno esclarecer los referentes y elementos que constituyen esta opción por el camino de la modernización. Sabemos que este olvido o descuido nace de la misma visión de progreso y carácter adoptado por la filosofía de la Ilustración francesa con respecto al tiempo histórico ${ }^{64}$.

Los clásicos del Derecho Natural de la vertiente neo-escolástica de la Escuela de Salamanca (Francisco Vitoria. De Jure belli Hispanorum in barbaros, 1532; Diego Saavedra Fajardo, Bartolomé de las Casas Brevísima Destrucción de las Indias, 1552; Juan Ginés de Sepúlveda Democrates Alter, 1550) estuvieron ligados a la justificación de un orden social determinado -al comienzo ligado a la Monarquía y Estado Confesional- (o también la ideología del Imperio Cristiano Vs. Carvajal, P., 2010) desde el Descubrimiento y Conquista de América hasta la Colonia. Luego, junto a otros elementos del iluminismo francés, en la emancipación política estuvieron ligados a la vertiente moderna de esta corriente filosófica de organización del Estado y fundación de la República ${ }^{65}$. Con la gran salvedad de que en nuestro caso, como ha conceptualizado Sol Serrano, nuestra República Liberal Moderna fue por mucho tiempo también una

62 Foucault, Michel. El Nacimiento de la Biopolitica. Traducción: H. Pons, Buenos Aires, Argentina: Fondo Cultura Económica, 2007, p. 20.

63 Jocelyn-Holt, Alfredo. op cit. (n.6), p. 107.

64 White, Hayden. Metahistoria la imaginación histórica en la Europa del siglo XIX. Traducción Stella Mastrangelo. México D.F., México: Fondo Cultura Económica, 1992, p. 69.

65 La importancia del lenguaje político republicano y la valoración de las ideas ilustradas especialmente francesas en: LASTARRIA, José Victorino. Discurso de inauguración a una sociedad de literatura de Santiago, Sesión 3 de mayo de 1842, Valparaíso, Chile. Véase. Gazmuri, Cristian. op cit. (n.6), p. 20 y ss. Donoso Ricardo. Las Ideas Politicas en Chile. Santiago, Chile: Editorial Universitaria, 1967, p. 28. Jocelyn-Holt, Alfredo. op cit. (n .6), p. 151. 
Republica Católica ${ }^{66}$. Es decir, la experiencia juntista emancipadora de la elite intelectual criolla, que celebra este año su bicentenario, heredó definitivamente a la posteridad los conceptos republicanos de organización de gobierno moderno, pero no necesariamente de organización de sociedad moderna.

La monarquía borbónica había sustituido el Patronato Regio, la concesión papal otorgada a los Reyes Católicos para gobernar la iglesia americana, por un regalismo que se entendió en la República como un derecho del Estado, porque la República buscaba apoyar su legitimidad política en nuevas instancias distintas a la legitimidad monárquica ${ }^{67}$. Sabemos que esta búsqueda de legitimidad moderna -principalmente en la etapa de ensayos constitucionales o anarquía institucional- fracasó en su intento y se estructuró en cambio una República conservadora, presidencialista y católica, muy cercana en apariencia al recuerdo monárquico al que se estaba acostumbrado a venerar, respetar y obedecer. El discurso político centrado en el pensamiento medieval cristiano de la monarquía hispánica era una "unidad anclada en la Tradición" 68 y tenía por tal una legitimidad político-social de la que carecía el mundo protestante y, en general, las nuevas formas de organización política moderna ${ }^{69}$. Es por ello que el Estado Moderno se había fundado en Europa en las inveteradas costumbres o leyes fundamentales del reino (fuente de legitimidad tradicional) y el problema para el pensamiento político republicano-liberal del siglo XVIII y XIX justamente fue ese: ¿Dónde encontrar una fuente tradicional de legitimidad parecida o simplemente una nueva? La monarquía absoluta en Europa encontraba, comenta Huesbe, sus fundamentos y legitimidad en la historia. La obra de Pufendorf y de los ilustrados del siglo XVIII sirvió como elemento de legitimidad del poder político en su forma moderna -secular y racional-, porque sus teorías partieron, así como la mayoría de los juristas protestantes, de la reflexión sobre profundos traumas sociales que afectaron por siglos la sensibilidad, mentalidad e ideas de la población general europea con respecto al papel de la autoridad política, el origen de su poder y la naturaleza del mismo ${ }^{70}$. Pero, por sobre todo, nace de la necesidad imperante de crear un nuevo referente político que situara a los ciudadanos en el centro de la

66 La Iglesia Católica, dice Serrano, pasaba a ocupar lugar en la esfera pública moderna o sociedad civil (Entre el Estado o Público y la vida privada) y desde allí, compartiendo lugar con otras formas de religión o ideología, luchar por su antigua preponderancia social, política y cultural: "El terror de la iglesia era quedar relegada precisamente allí donde la relegaron los teóricos de la secularización: a la conciencia individual”. Serrano, Sol. ¿Qué hacer con Dios en la República? Santiago, Chile: Fondo Cultura Económica, 2008, p. 23.

67 Castillo, Vasco. La creación de la República. La Filosofía Pública en Chile 1810-1830. Santiago, Chile: Editorial LOM, 2009, p. 21 y ss.

68 Huesbe Llanos, Marco. Teoría, Administración y Participación... op. cit. (n.21), p. 134 y ss.

69 El absolutismo político es la mejor forma de gobierno en la época porque encuentra sus fundamentos en la historia dice Huesbe, por tanto, la ley regia o fundamental se apoya en las inveteradas costumbres. Ibid. p. 62.

70 Tenenti, Alberto. Libertinaje y Herejía a mediados del siglo XVI y comienzos del XVII herejías y sociedades en la Europa preindustrial, siglos XI- XVIII. México D.F., México,: Siglo Veintiuno Editores S.A, 1996, p. 232. Koselleck, Reinhart. Critica y Crisis Un estudio sobre la patogénesis del mundo burgués. Madrid, España: Editorial Trotta, 2007, p. 32. 
vida pública y en el cual fuesen capaces por sí mismos, mediante un contrato social, conformar nada menos que el origen del poder político, ser su única fuente de legitimidad y, a la vez, convertirse en único límite ante el abuso del poder de los gobernante.

En este sentido, el proyecto ilustrado, como han planteado muchos historiadores, es un proyecto incompleto y readaptado a la realidad indígena de América Latina que finalmente fracasa por su descontextualización ${ }^{71}$. Prueba de ello fue que la República Liberal dejó de entenderse en Chile como había sido herencia del influyente pensamiento ilustrado, como el lugar o ámbito de la libertad política (República Conservadora). Pero también y con mayores consecuencias políticas y sociales para el devenir del siglo que partía, la República Liberal dejó de ser entendida como el ámbito donde cada hombre podía escoger y reconocer autónomamente normas éticas de su preferencia. En el ámbito de la moral, en el caso nacional, la República fijó la unidad religiosa y la Iglesia Católica fue la religión oficial e indiscutida hasta el siglo XX. Hoy en día, la confrontación ideológica iniciada por el liberalismo decimonónico entre Estado confesional y Estado laico, que atraviesa con enormes consecuencias todo el siglo XIX en Chile, ha sido superada históricamente y se atribuye un tratamiento intelectual de carácter científico, neutral a los ordenamientos confesionales y a las manifestaciones religiosas de la sociedad, dejando de cierta forma rezagado este tipo de estudios ${ }^{72}$. Si bien Pufendorf podría haber ayudado a sentar una nueva cosmovisión ${ }^{73}$, distinta a la tradicional tutela eclesiástica forjadora de una imagen monolítica del mundo moral y político del llamado legado espiritual español, su efecto en nuestro ámbito intelectual es improbable y solo podemos esbozar conjunciones acerca de su posible influencia en el ámbito de las ideas políticas liberales. En ámbitos como el religioso, en nuestro caso y en otros en América Latina, el pensamiento ilustrado (Deísmo) simplemente no fue considerado dentro de la reflexión política.

71 Jocelyn-Holt, Alfredo. op. cit. (n.6), p.118.

72 "En el extremo opuesto a esta concepción dictatorial y tiránica de la función del Estado como controlador del pensamiento y de la ideología religiosa de sus súbditos, el Derecho estatal de libertad religiosa aparece amparado en todos los foros internacionales como un derecho de primera generación; como un derecho fundamental de la persona humana que el Estado no crea sino que reconoce y tutela”. Salinas Araneda Carlos. Lecciones de Derecho Eclesiástico del Estado de Chile, Valparaíso, Chile: Ediciones Universitarias de Valparaíso - Pontificia Universidad Católica de Valparaíso, 2004, Prólogo, p. 15.

73 Geyer, Bodo y Goerlich, Helmut (compil.). op cit. (n.61), p. 33. 


\section{REFERENCIAS BIBLIOGRÁFICAS}

Bello, Andrés. Principios de derecho internacional. Buenos Aires, Argentina: Edit. Atalaya, 1946, vol. IV.

Carpintero Benítez, F. Del Derecho Natura Medieval al Derecho Natural Moderno: Fernando Vázquez de Menchaca. Salamanca, España: Ediciones Universidad de Salamanca, 1997.

Castillo, Vasco. La Creación de la Republica La Filosofía Pública en Chile 1810-1830. Santiago, Chile: Editorial LOM, 2009.

Collier, Simon. Ideas and Politics of chilean Independence 1808-183. Cambridge, Inglaterra: Cambridge University Press, 1967.

Defourneaux, Marcelin. Inquisición y censura de libros en la España del siglo XVIII. Madrid, España: Editorial Taurus, 1973.

Eyzaguirre, Jaime. Ideario y Ruta de la Emancipación chilena. -24a edición- Santiago, Chile: Editorial Universitaria, 1996.

Foucault, Michel. El Nacimiento de la Biopolítica. Traducción: H. Pons, Buenos Aires, Argentina: Fondo Cultura Económica, 2007.

Gazmuri, Cristián, Libros e ideas políticas ilustradas en la independencia de Chile. En: Loyola, Manuel y Grez, Sergio (comp.). Los proyectos Nacionales en el Pensamiento Politico y Social Chileno del Siglo XIX. Santiago, Chile: Ediciones UCSH, 2002.

Gazmuri, Cristián y Krebs, Ricardo (comp.). La Revolución Francesa y Chile. Santiago, Chile: Ediciones Universitarias, 1999.

Geyer, Bodo y Goerlich, Helmut (compil.). Samuel Pufendorf und seine wirkungen bis auf die heutige zeit. BadenBaden, Alemania: Nomos. 1996.

Gierke, Otto. Natural Law and the Theory of Society1500 to 1800. Traducción e Introducción Ernest Barker, Boston, Estados Unidos: Editorial Beacon Press, 1960.

Góngora, Mario. Studies in the Colonial History of Spanish America. Traducción de Richard Southern Cambridge, Inglaterra: Cambridge University Press, 1975.

Hazard, Paul. La Crisis de la Conciencia Europea. Madrid, España: Editorial Pegaso, 1974.

Hochstrasser, Tim. Natural Law Theories in the Early Enlightenment. Cambridge, Inglaterra: Cambridge University Press, 2000.

Henríquez, Camilo. Proclama de Quirino Lemachez. En: Henríquez, Camilo y Martínez de Rozas. Páginas de la independencia nacional. <en línea> Santiago, Chile: Editorial del Pacífico, Instituto de Estudios Políticos, 1976. Disponible en la World Wide Web: http://www.memoriachilena.cl/temas/documento_detalle. asp?id=MC0001691

Huesbe, Marco (comp.). Arte y Política del Barroco. Valparaíso, Chile: Editorial Universitarias de Valparaíso, 2000.

Huesbe Llanos, Marco. Teoría, Administración y Participación en el Estado Moderno. Bodino, Arnisaeus, Beza. Valparaíso, Chile: Editorial: Ediciones Universitarias de Valparaíso, 2008, p. 37. Una sistematización del pensamiento político moderno alemán en: Carvajal, Patricio. La Crisis del Estado Moderno. La Staatslehre europea de Martin Luther a Petra Kelly. Valparaíso, Chile: Ediciones Facultad de Humanidades Universidad de Playa Ancha, 2010, p.46.

" "La teoría política de Samuel Pufendorf a través de su comentario a la constitución del imperio romanogermánico (1667)", en: Revista Estudios Históricos -Jurídicos <en línea> 2009, n.31 [citado e 13 de Enero de 2011], pp. 427-445. Disponible en la World Wide Web: <http://www.scielo.cl/scielo.php?script=sci_ar ttext\&pid=S071654552009000100016\&lng >=es\&nrm=iso>. ISSN 0716-5455. doi: 10.4067/S071654552009000100016. 
Jellenik, Georg et al. Orígenes de la Declaración de los Derechos del Hombre y el Ciudadano. Traducción Adolfo Posada, Madrid, España: Editorial Nacional, 1984.

Jocelyn- Holt, Alfredo. La Independencia de Chile Tradición, Modernización y Mito. -2a. edición- Santiago, Chile: Editorial Planeta/Ariel, 1999.

Koselleck, Reinhart. Critica y Crisis Un estudio sobre la patogénesis del mundo burgués. Madrid, España: Editorial Trotta, 2007.

Leibniz, Gottfried Wilhelm. "Algunas observaciones sobre las ideas fundamentales", de Samuel Pufendorf, dirigidas a G. W. Molano. En su: Escritos de Filosofia Jurídica y Política. Madrid, Espańa: Fondo Cultura Económica. 2001.

Oro Tapia, Luis. "Notas sobre el equilibrio de poder", en: Revista Enfoques, No 12, Vol. VII, 2010. Santiago, Chile: Universidad Central, Santiago.

Pufendorf, Samuel. "The whole duty of man, according to the law of nature". Edición al inglés de Ian Hunter y David Saunders. Indianapolis, Estados Unidos: Editorial Liberty Fund, 2003.

La Constitución del Imperio Alemán 1667. Traducción y Estudio Preliminar Marco Huesbe. Valparaíso, Chile: Edit. Edeval, 2009.

The nature and qualification of religion in reference to civil society. Traducción al Inglés Jodcus Crull, Edición Simone Zurbuchen, Indianápolis, Estados Unidos: Editorial Liberty Fund, 2002.

Rousseau, Jean. Jacques. El Contrato Social. Trad. Madrid, España: Editorial Alba, 1998.

Rus Rufino, Samuel. Estudio Preliminar. En: Pufendorf, Samuel. De los deberes del Hombre y del Ciudadano en Dos Libros. -2a. edición español- Traducción Samuel Rus Rufino, Madrid, España: Editorial Estudios Constitucionales, 2002.

Salinas Araneda Carlos. Lecciones de Derecho Eclesiástico del Estado de Chile. Valparaíso, Chile: Ediciones Universitarias de Valparaíso - Pontificia Universidad Católica de Valparaíso, 2004.

Serrano, Sol. ¿Qué hacer con Dios en la República? Santiago, Chile: Fondo Cultura Económica, 2008.

Skinner, Quentin. “Una genealogía del Estado Moderno”, en: Estudios Públicos, No 118, 2010, pp. 31 y ss. Santiago, Chile: Centro de Estudios Públicos.

Stuven, Ana María. La Seducción de un Orden: Las Elites y la construcción de Chile en las polémicas culturales y politicas del siglo XIX. Santiago, Chile: Ediciones Universidad Católica de Chile, 2000.

TenentI, Alberto. Libertinaje y Herejía a mediados del siglo XVI y comienzos del XVII herejías y sociedades en la Europa preindustrial, siglos XI- XVIII. México DF, México: Siglo Veintiuno Editores S.A, 1996.

Tuck, Richard, Introduction. En: Grotius, H. The Rights of War and Peace. Indianapolis, Estados Unidos: Editorial Liberty Fund, 2005.

Van Gelderen, Martin y SKinner, Quentin. (edts.). Republicanism: Republicanism and constitutionalism in early modern Europe. Cambridge, Inglaterra: Cambridge University Press, 2002.

Villalobos, Sergio. Tradición y Reforma en 1810. Santiago, Chile: Editorial Universitaria, Ediciones de la Universidad de Chile, 1961.

Whaley, Joachim. A Tolerant Society? Religious Toleration in the Holy Roman Empire. En: GreLl, Ole Peter y Porter, Roy. (Edits). Toleration in Enlightenment Europe. Cambridge, Inglaterra: Cambridge University Press, 2000.

Welzel, Hans. Die Naturrechtslehre Samuel Pufendorfs: ein Beitrag zur Ideengeschichte d. 17. u. 18. Jh. -2a. ediciónBerlin, Alemania: Editorial de Gruyter, 1986.

WieAcker, Franz. Historia del Derecho Privado en la época Moderna. Madrid, España: Editorial Aguilar, 1957.

Wolf, Erik. Grosse Rechtdenker der deutschen Geistesgeschichte. Tübinge, Alemania: Editorial J. C. B. Mohr, 1951. 